\title{
Saudi Gender Emotional Expressions in Using Instagram
}

\author{
Dr. Ibtesam AbdulAziz Bajri ${ }^{1} \&$ Nada Abdulmajeed Lashkar ${ }^{1}$ \\ ${ }^{1}$ Department of English Language, University of Jeddah, Saudi Arabia \\ Correspondence: Dr. Ibtesam AbdulAziz Bajri, Department of English Language, University of Jeddah, Saudi \\ Arabia
}

Received: February 6, 2020

Accepted: April 20, 2020

Online Published: April 23, 2020

doi: 10.5539/elt.v13n5p94

URL: https://doi.org/10.5539/elt.v13n5p94

\begin{abstract}
There are plentiful studies exploring gender emotional differences. Gender and emotion stereotypes make people believe that there are certain emotions associated with each gender and this is supported by many studies. The purpose of this research is to analyze the emotional expressions of Saudi men and women in Instagram, a social networking service. This paper aims to explore the Saudi differences of emotional expressions. Also, if gender emotion stereotypes apply on these expressions or not. Data is collected through corpus analysis of Arabic comments for a certain post on Instagram. The results of this study demonstrate that there are differences in Saudis' expressions of emotions in which each gender uses different expressions. Additionally, gender stereotypes of emotions are applied to their emotional expressions that is men express negative emotions more while women express positive emotions. Another result is that women are found to be more emotional than men. Overall, the findings contribute to increase understanding of online emotional expressions of both Saudi genders.
\end{abstract}

Keywords: Gender, stereotype, Instagram, emotional expressions, online

\section{Introduction}

Linguistic gender differences is one of the topics that sociolinguists and researchers have been addressing for a long time. Our everyday interactions with both genders show how different men and women are from each other in their communicative styles and behaviors (Csepes, et al., 2015). Gender difference in expressing emotions is one aspect that shows the linguistic differences between them. Nowadays, social networking sites are a significant part of everyday interaction. Vermeulen, et al., (2018) claim that "social media are indeed rich in emotions" (4). Thus, an analysis of emotional expressions in online social media discourse, especially between genders, is needed to today's society (Parkins, 2012). The current research attempts to examine the online emotional expressions expressed by Saudi men and women to see the differences among them.

Expressing emotions are important in interpersonal interactions and in expressing one's feelings and experiences. As maintained by Skinner (2013), expressing an emotion is the way a person conveys an emotional experience through nonverbal and verbal behavior. Furthermore, Forgas (2006) argues that "emotions appear to influence what we notice, what we learn, what we remember, and ultimately the kinds of judgments and decisions we make" (273). According to Shields (2002), the word 'emotional' is used by people "to refer to what a person is doing in a particular situation" and "to describe an enduring feature of personality" (5). However, emotional expressions are different from emotional experiences because one can experience emotions without expressing them. There are two classes of functions for emotional expressions: to prepare the organism to respond to recurrent stimuli in the environment, and to communicate critical social information (Darwin, 1872).

Many works examine the verbal and non-verbal communication of emotions in various cultures and contexts between genders (e.g., Chaplin \& Aldao, 2013; Brown, Craig, \& Halberstadt, 2015; Chaplin, 2015; Aznar \& Tenenbaum, 2019). Gender emotion stereotypes is one of the prominent topics that has been studied and examined until recently. For example, Ellemers (2018) explores gender emotion stereotypes to investigate its impact on the way people perceive others and remember information about themselves and other individuals. Further, gender emotion stereotypes have been studied to see how they affect leadership perceptions (Fischbach, Lichtenthaler, \& Horstmann, 2015). These examples demonstrate that knowing gender emotion stereotypes is beneficial in our daily life to understand ourselves and others in a better way. However, Shields (2002) states that "stereotypes offer a way to think about a group without thinking through the nuance required when one 
considers the individual members of the group" (6). Thus, stereotypes of gender and emotion can be inaccurate when they are generalized to all individuals.

\subsection{Statement of Problem}

Several studies have been conducted to examine gender differences in online language use such as Holmberg and Hellsten (2015) and Waterloo, et al. (2018). Gender difference in communicating climate change on Twitter is investigated by Holmberg and Hellsten (2015), while the norms of expressing emotions on social media by both genders are explored by Waterloo, et al. (2018). However, none examines online language use of Saudi male and female emotional expressions and compare their online comments in Arabic language. This research investigates the differences of emotional expressions between Saudis based on their online comments. This study has a significant contribution to the Saudi society by providing a complete overview of how men and women's expressions of emotions could be different from each other and in what way. This benefits the individuals to understand each other and consider these differences in order to communicate successfully.

\subsection{Research Objective}

The current research aims to study the differences of the emotional expressions produced by both Saudi men and women and if emotional stereotypes apply to gender expressions or not. This investigation is done by analyzing Instagram comments of Saudi males and females for a certain post in a Saudi news account.

\subsection{Research Questions}

This paper attempts to answer the following research questions in order to fill the previously mentioned gap:

1. Are there any differences between Saudi male and female regarding their emotional expressions?

2. Do Saudi male and female emotional stereotypes apply on online expressions?

\section{Literature Review}

Gender is a term used to describe categories that are socially constructed based on sex. Most societies work with two genders, masculine and feminine, and the category of gender is treated as a simple binary opposition. Nevertheless, recent theories challenge this by conceptualizing gender as plural including a range of masculinities and femininities (Coates, 2015). Further, Coates argues that people are curious about men and women's way of talk and if there are linguistic gender differences between them. According to Kachru, Kachru, and Sridhar (2008), there is a fundamental difference between men and women and this difference is reflected in their language use.

Gender and emotion are aspects that gender differences in language use is highly shown in. Gender emotion stereotypes are observed in preschool children which have been sophisticated as they grow up (Birnbaum, Nosanchuk, \& Croll, 1980; Kelly \& Hutson - Comeaux, 2002). People will consider expressing their emotions 'correctly' to be socially acceptable according to their gender and illustrate their social competence. This can be explained by the reason of that we are subconsciously aware of the way we express our emotions which significantly affects our social relationships (Campos, et al., 1994). As a result of these views, women are believed to be more emotionally expressive than men (Fabes \& Martin, 1991). It is worth mentioning that gender emotion stereotypes are about expressing emotions rather than experiencing them. Moreover, gender and emotion stereotypes can be imprecise and ignore the cultural, situational and individual differences in both males and females' emotional expressiveness (Brody, 1996).

Several studies have been conducted to explore gender emotion stereotypes within different contexts. For instance, Plant, et al. (2000) examine gender stereotypes of emotions, and their relationship to the emotional expressions produced by both of them. The study is conducted on 117 undergraduate students who fill two questionnaires based on Fabes and Martin's (1991) questionnaire. The results illustrate that there are several emotions believed to be expressed by women more often than men such as happiness, love, and surprise. On the other hand, anger, sadness and pride are emotions believed to be expressed more by men.

Gender emotion stereotypes are context-specific that is they vary depending on the situational factors like the emotional event's contextual nature. A study conducted by Kelly and Hutson-Comeaux (1999) argues that gender stereotypes of emotions are context-dependent. The nature of the context whether it is an achievement, or an interpersonal context has a strong effect on people's emotional expressions in happy and sad emotional events. A number of undergraduate students from both genders read scenarios of happy, sad, and angry emotional events that appear in different contexts to judge how characteristic of reactions to the events would be for a woman and for a man. People believe women should be more expressive of emotions than men, but the results demonstrate that women only do this in an interpersonal context. Further, the stereotype of the unemotional male is quite the 
opposite. Men's overreactions to happy and sad events are more noticeable than in women. These findings demonstrate that the general notions of the unemotional man and emotional woman are in fact context dependent.

Gender differences in expressing their emotions are also a prominent topic in online platforms studies. Thelwall, Wilkinson, and Uppal (2010) examine MySpace comments to analyze the emotions presented in these comments regarding gender and age. The data of this study consists of 819 comments to or from American users. They are collected and classified based on the strength of positive and negative emotions. Two thirds of the collected data contain positive emotions, and few express negative emotions. The findings of the research state that females give and receive more positive comments than males. However, there is no significant difference for the negative comments. Therefore, females might be considered more successful in social networking due to their ability to textually tackle positive affect.

Gender and emotion stereotypes are also investigated in children's emotional expressions. A study conducted by Martin (2017) assesses the extent in which gender emotion stereotypes diffuse in children's television programs, either in educational or non-educational settings. The collected data consists of 4 entertainment programs and 4 educational programs for children. Programs are coded according to the number of men and women characters. Additionally, they are coded for the displayed emotions by each character including anger, happiness, and sadness. The findings indicate that males are found to express more emotions than females and that male characters outnumber females in the programs. Further, educational programs are similar to each other regarding the portrayals of emotion for males and females.

Many studies examine whether men or women are more expressive of emotions, which emotions belong to whom, and if gender stereotypes are context-dependent or not (Plant, et al., 2000; Kelly \& Hutson-Comeaux, 1999). Yet, little studies have been conducted about gender emotions differences in social media, especially on Instagram comments in Saudi Arabia (SA). The current research investigates the differences of the emotional expressions between Saudi males and females based on their comments on Instagram for a particular chosen post. The importance of this research is to determine if there are differences between Saudi genders emotional expressions, and whether the stereotypes of emotions are applied on these emotional expressions produced by them or not. This is for the reason that gender and emotion stereotypes could fail to generalize broadly.

\section{Methodology}

\subsection{Data Collection}

A sample of 120 Instagram comments is collected randomly for this research and they are analyzed to answer research questions. The data collection method is designed to get Instagram comments of Saudi males and females in order to analyze the differences of their emotional expressions. A specific popular post from a verified account called Saudinews50 is chosen from Instagram to collect the data. This post announces that Saudi women are officially allowed to drive in Saudi Arabia. This post is chosen because it has a numerous number of comments containing mixed emotional expressions of both genders.

\subsection{Participants}

The participants are from various social classes. Specifically, they vary in their age, level of education, social status and geographical locations within Saudi Arabia. This is because the comments are collected from Instagram and the information of its users are limited based on what they have entered in their profiles.

\subsection{Data Analysis}

The data are collected randomly from Instagram which are around 120 comments of the post. A qualitative approach is used as the collected data is analyzed through corpus analysis to compare the different comments of Saudi men and women on Instagram. The data have been selected from participants who specified 'Arabic' as the language of their comments. The gender of the participants is identified by comparing their first names, as written in their Instagram profiles. After collecting 120 comments of both genders, they are analyzed to find the most frequently used expressions of emotions. Then, they are transliterated based on the transliteration system of the International Journal of Middle East Studies (IJMES) since they are written in Arabic (cited in "International Journal of Middle East Studies," 1970). These steps are done in order to answer the research questions.

\section{Results and Discussion}

This research is designed to investigate the differences in the emotional expressions used by Saudi male and female and if these expressions apply on stereotypes of emotions or not. The results of the study show that the first research question is clearly answered in which there are noticeable Saudi male and female differences in 
their emotions. This is in line with the research by Csepes, et al. (2015) and Kachru, et al. (2008) in which they state that males and females differ in their communicative styles and language use. The data in Figure (1) and (2) below illustrate that Saudi males and females vary in their choices of the emotional expressions and of their indications either negative or positive. However, there are three similar expressions that they share: (1) "allaāh yustur" praying Allah to prevent anything bad that will happen, (2) "mabruūk" congratulating women for allowing them to drive, and (3) "bittawfiīq" wishing women a good luck. Nevertheless, these similarities are still not significant based on the number of the expressions that they do not share.

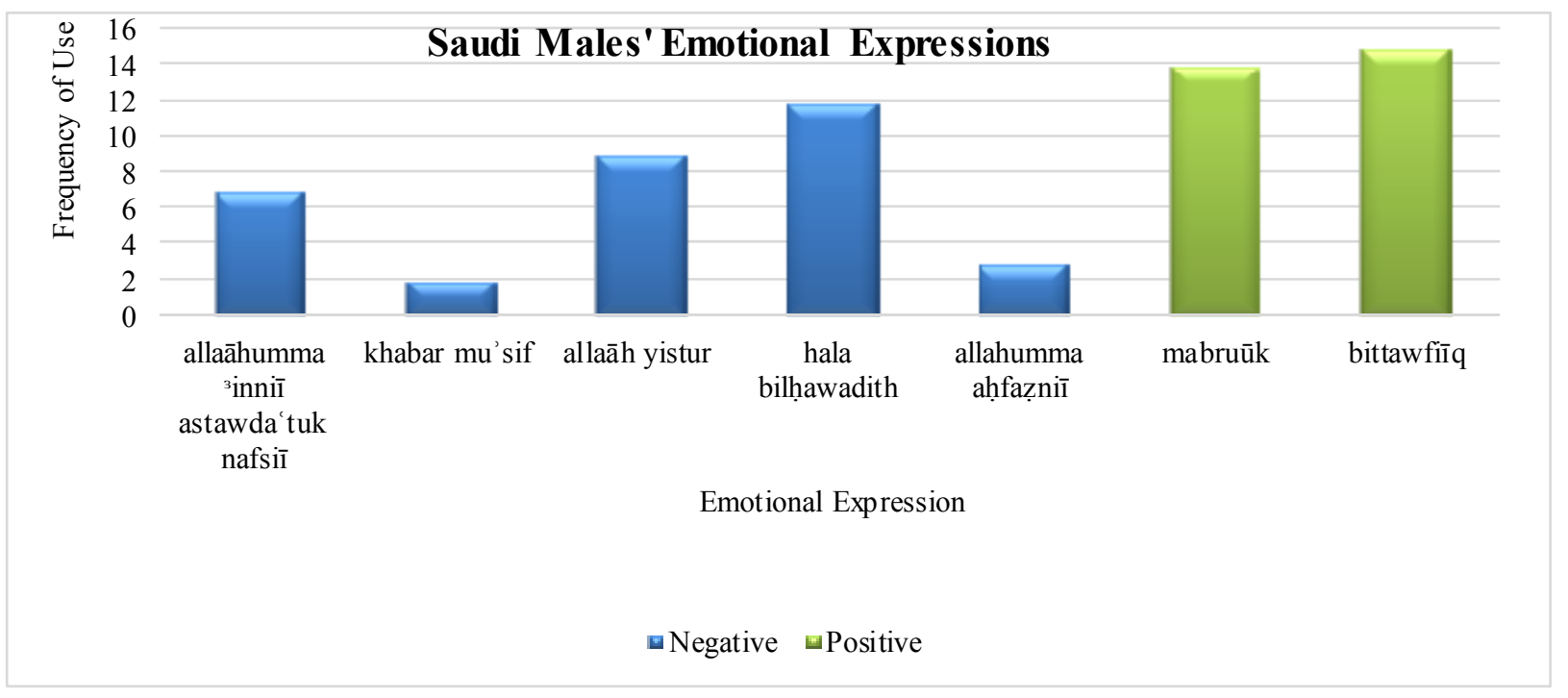

Figure 1. Saudi Males' Emotional Expressions

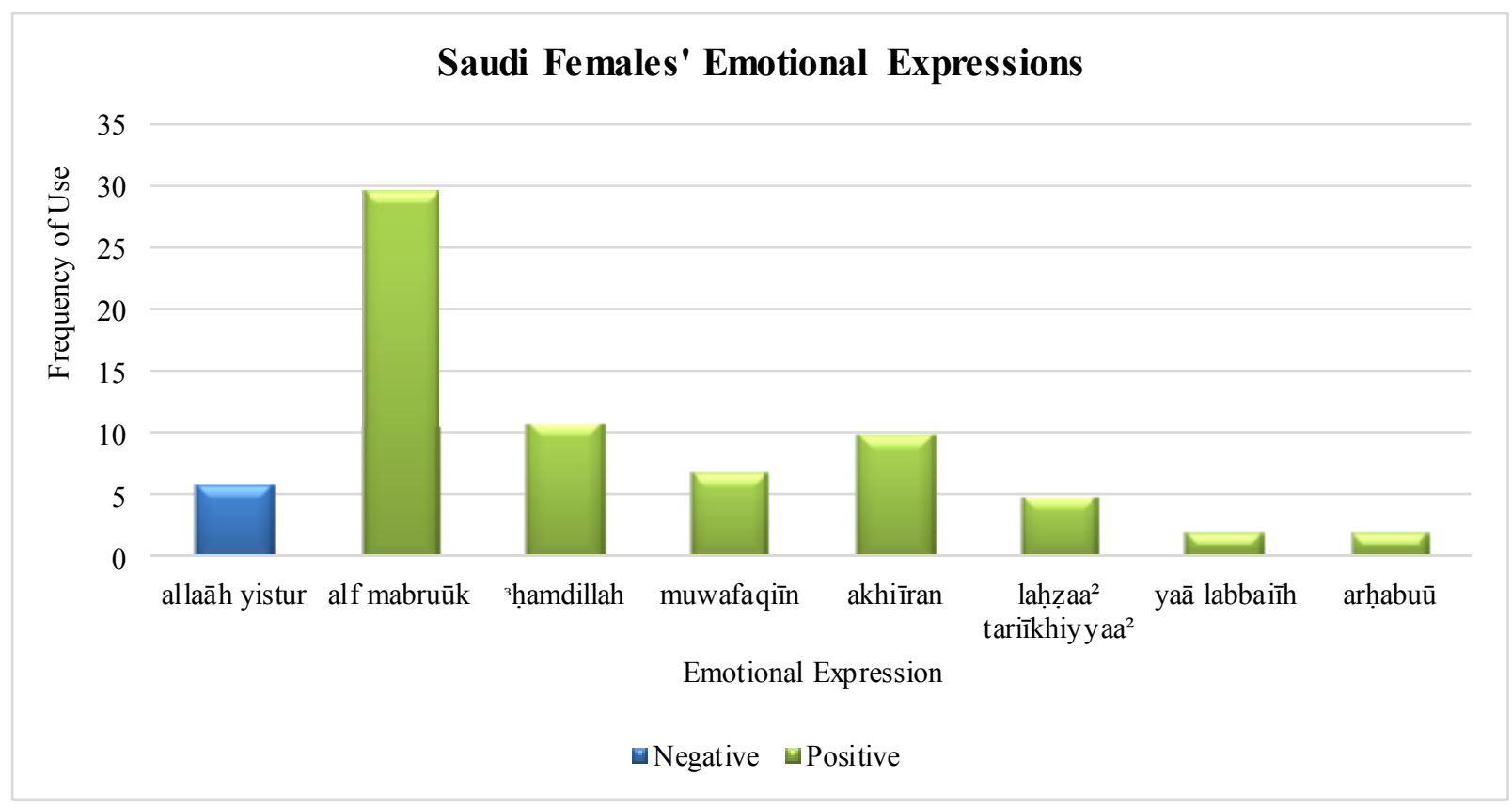

Figure 2. Saudi Females' Emotional Expressions

Regarding the second research question, the graphs (1) and (2) illustrate that men express more negative emotions than women. Five negative emotions are expressed by men: (1) "allaāhumma inniī astawda 'tuk nafsiī" praying Allah to protect him, (2) "khabar mu'sif" expressing that this is unfortunate news, (3) "allaāh yustur" praying Allah to prevent bad things, (4) "hala bilhawadith" welcoming accidents as sarcastic, and (5) "allahumma ahfaznī" praying Allah to keep him safe. On the other hand, only one negative emotion is expressed by women that is "allaāh yustur". This finding agrees with the study of Plant, et al. (2000) which indicates that 
negative emotions are expressed more by men such as sadness. However, this result contradicts with Thelwall, et al. (2010) in which there is not much difference between males and females regarding their negative emotional expressions. This contradiction indicates that gender and emotion stereotypes could fail to generalize to all genders in all cultures.

In terms of the positive emotions, men express two positive emotions "mabruūk" and "bittawfiīq", while females express seven positive emotions out of eight: (1) "alf mabruūk" expressing their happiness by congratulating themselves and other females, (2) "shamdillah" thanking Allah for this decision, (3) "muwafaqiīn" wishing themselves and other females a good luck, (4) "akhiīran" expressing their happiness and their long waiting by saying finally, (5) "laḥzaa ${ }^{2}$ tarī̄khiyyaa ${ }^{2 "}$ meaning that this is a historical moment, (6) "yaā labbaī̄n" which is a Saudi expression of expressing happiness and gratitude, and (7) "arḥabuū" welcoming this great news happily. This finding is in line with Plant, et al. (2000) and Thelwall, et al. (2010) where they find out that positive emotions such as happiness are expressed more by women.

Additionally, findings show that women are more emotionally expressive than men. The data in figure 2 shows that females outnumber males in expressing emotions very obviously where they reach thirty comments producing the most frequent expression "alf mabruūk". In contrast, the highest number of males' comments reach fifteen comments only using the expression "bittawfiīq". This finding seems consistent with the results reported by Fabes and Martin (1991) in which women express their emotions more than men. On the other hand, it contradicts with the findings reported by Martin (2017) that male characters in children's programs show higher levels of emotions than females. Therefore, it is clear now that gender emotion stereotypes do apply on the Saudi community and still dominant until present which answers the second question of the current research.

\section{Conclusion}

As maintained earlier in this research, previous studies have found that there are certain gender stereotypes of emotional expressions, and that some certain emotions are believed to be more characteristic of women and men (Plant, et al., 2000). These stereotypes give the society specific perspectives to view what is socially acceptable and what is not regarding men and women's emotional expressions. The current researchers expect that as the technology develops, gender stereotypes of emotions would be weakened, at least some of them, due to the usage of nicknames in online communication. The findings reveal that negative emotions are expressed more by men, while positive emotions are expressed more by women. In addition, it is found that women are the more expressive gender. This indicates that the stereotypical portrayals of gender and emotions are still powerful and dominant.

To the researchers' knowledge, no previous investigations on Saudi men and women emotional expressions within Instagram comments have been conducted. Therefore, the current research contributes to the literature of sociolinguistic studies and genders differences by exploring the emotional expressions of Saudi men and women in using online platforms. Additionally, the current research has a significant contribution to the Saudi community by enhancing the communication and the understanding between Saudi male and female when they express their emotions.

\section{Limitations of Study}

The selected post in Instagram "allowing women to drive in SA" is biased to women which might have affected the expressions of happiness and sadness for both genders. Thus, it is recommended to choose another less biased post for further research. It might be important to examine gender and emotion stereotypes of Saudis in face-to-face interactions by videotaping, observing or interviewing them in real life situations, because people tend to copy or imitate others' comments in online unlike their spontaneous speech in everyday life. It would also be important to specify some social factors such as age, and educational background to increase the accuracy and credibility of the results.

\section{References}

Aznar, A. \& Tenenbaum, H. R. (2019). Gender Comparisons in Mother-Child Emotion Talk: A Meta-Analysis. Sex Roles. https://doi.org/10.1007/s11199-019-01042-y

Birnbaum, D., Nosanchuk, T. \& Croll, W. (1980). Children's Stereotypes about Sex Differences in Emotionality. Sex Roles, 6(3), 435- 443. https://doi.org/10.1007/BF00287363

Brody, L. R. (1996). Gender and Emotion: Beyond Stereotypes. Journal of Social Issues, 53(2), 369-393. https://doi.org/10.1111/j.1540-4560.1997.tb02448.x 
Brown, G. L., Craig, A. B. \& Halberstadt, A. G. (2015). Parent Gender Differences in Emotion Socialization Behaviors Vary by Ethnicity and Child Gender. Parenting, 15(3), 135-157. https://doi.org/10.1080/15295192.2015.1053312

Campos, J. J., Mumme, D., Kermoian, R. \& Campos, R. G. (1994). A Functionalist Perspective on the Nature of Emotion. Japanese Journal of Research on Emotions, 2(1), 1-20. https://doi.org/10.4092/jsre.2.1

Chaplin, T. M. (2015). Gender and Emotion Expression: A Developmental Contextual Perspective. Emotion Review, 7(1), 14-21. https://doi.org/10.1177/1754073914544408

Chaplin, T. M. \& Aldao, A. (2013). Gender Differences in Emotion Expression in Children: A Meta-Analytic Review. Psychological Bulletin, 139(4), 735-765. https://doi.org/10.1037/a0030737

Coates, J. (2015). Women, Men and Language: A Sociolinguistic Account of Gender Differences in Language. London: Routledge. https://doi.org/10.4324/9781315645612

Csepes, I., Fekete, A., Kardos, E., Koczogh, H., Monos, K. \& Sanko, G. (2015). Challenges of the 21st Century: An In-Service Teacher Training Course for EFL Teachers. Debrecen: Debrecen University Press.

Darwin, C. (1872). The Origin of Species by Means of Natural Selection: Or the Preservation of Favoured Races in the Struggle for Life: The Descent of Man and Selection in Relation to Sex. New York, NY: Modern Library. https://doi.org/10.5962/bhl.title.61216

Ellemers, N. (2018). Gender Stereotypes. Annual Review of Psychology, 69(1), 275-298. https://doi.org/10.1146/annurev-psych-122216-011719

Fabes, R. A. \& Martin, C. L. (1991). Gender and Age Stereotypes of Emotionality. Personality and Social Psychology Bulletin, 17(5), 532-540. https://doi.org/10.1177/0146167291175008

Fischbach, A., Lichtenthaler, P. W. \& Horstmann, N. (2015). Leadership and Gender Stereotyping of Emotions. Journal of Personnel Psychology, 14(3), 153-162. https://doi.org/10.1027/1866-5888/a000136

Forgas, J.P. (2006). Affective Influences on Interpersonal Behavior: Towards Understanding the Role of Affect in Everyday Interactions. In J.P. Forgas (Ed.) Affect in Social Thinking and Behavior (269-290). New York, NY: Psychology Press.

Holmberg, K. \& Hellsten, I. (2015). Gender Differences in the Climate Change Communication on Twitter. Internet Research, 25(5), 811-828. https://doi.org/10.1108/IntR-07-2014-0179

International Journal of Middle East Studies. (1970). International Journal of Middle East Studies, 8(4). https://doi.org/10.1017/s002074380002626x

Kachru, B. B., Kachru, Y. \& Sridhar, S. N. (2008). Language in South Asia: Language and Gender. Cambridge: Cambridge University Press. https://doi.org/10.1017/CBO9780511619069

Kelly, J. R. \& Hutson-Comeaux, S. L. (1999). Gender-Emotion Stereotypes are Context Specific. Sex Roles, 40(1-2), 107-120. https://doi.org/10.1023/A:1018834501996

Kelly, J. R. \& Hutson - Comeaux, S.L. (2002). Gender Stereotypes of Emotional Reactions: How We Judge an Emotion as Valid. Sex Roles, 47(1-2), 1 - 10. https://doi.org/10.1023/A:1020657301981

Martin, R. (2017). Gender and Emotion Stereotypes in Children's Television. Journal of Broadcasting \& Electronic Media, 61(3), 499-517. https://doi.org/10.1080/08838151.2017.1344667

Parkins, R. (2012). Gender and Emotional Expressiveness: An Analysis of Prosodic Features in Emotional Expression. Queensland: Griffith University.

Plant, E. A., Hyde, J. S., Keltner, D. \& Devine, P. G. (2000). The Gender Stereotyping of Emotions. Psychology of Women Quarterly, 24(1), 81-92. https://doi.org/10.1111/j.1471-6402.2000.tb01024.x

Shields, S. A. (2002). Speaking from the Heart: Gender and the Social Meaning of Emotion. Cambridge: Cambridge University Press.

Skinner M. (2013). Emotional Expression. In M.D. Gellman \& J.R. Turner (Eds.) Encyclopedia of Behavioral Medicine (673-675). New York, NY: Springer.

Thelwall, M., Wilkinson, D. \& Uppal, S. (2010). Data Mining Emotion in Social Network Communication: Gender Differences in MySpace. Journal of the American Society for Information Science and Technology, 61(1), 190-199. https://doi.org/10.1002/asi.21180 
Vermeulen, A., Vandebosch, H. \& Heirman, W. (2018). \# Smiling,\# Venting, or Both? Adolescents' Social Sharing of Emotions on Social Media. Computers in Human Behavior, 84, 211-219. https://doi.org/10.1016/j.chb.2018.02.022

Waterloo, S. F., Baumgartner, S. E., Peter, J. \& Valkenburg, P. M. (2018). Norms of Online Expressions of Emotion: Comparing Facebook, Twitter, Instagram, and WhatsApp. New Media \& Society, 20(5), 1813-1831. https://doi.org/10.1177/1461444817707349

\section{Appendix 1}

IJMES transliteration system of Arabic consonants and vowels (cited in "International Journal of Middle East Studies," 1970).

\begin{tabular}{|c|c|}
\hline \multicolumn{2}{|c|}{ Arabic Consonants } \\
\hline Consonant & Symbol \\
\hline$c$ & , \\
\hline ب & $\mathrm{b}$ \\
\hline ت & $\mathrm{t}$ \\
\hline$ث$ & th \\
\hline ج & $\mathrm{j}$ \\
\hline$\tau$ & ha \\
\hline$\dot{\tau}$ & $\mathrm{kh}$ \\
\hline د & $\mathrm{d}$ \\
\hline$\dot{~}$ & $\mathrm{dh}$ \\
\hline Ј & $\mathrm{r}$ \\
\hline j & $\mathrm{z}$ \\
\hline س س & $\mathrm{s}$ \\
\hline ش & sh \\
\hline ص ص ص la la & ș \\
\hline ض & ḍ \\
\hline b & $\mathrm{t}$ \\
\hline ط & $\mathrm{z}$ \\
\hline$\varepsilon$ & ' \\
\hline$\dot{\varepsilon}$ & gh \\
\hline ف & $\mathrm{f}$ \\
\hline ق & q \\
\hline كs & $\mathrm{k}$ \\
\hline 」 & 1 \\
\hline s & $\mathrm{m}$ \\
\hline ن & $\mathrm{n}$ \\
\hline 。 & $\mathrm{h}$ \\
\hline 9 & $\mathrm{w}$ \\
\hline ي & $\mathrm{y}$ \\
\hline$\dot{0}$ & $a^{2}$ \\
\hline ال ال & 3 \\
\hline
\end{tabular}

Arabic Vowels

\begin{tabular}{cc}
\hline Short & Symbol \\
\hline$\infty$ & $\mathrm{a}$ \\
$\varnothing$ & $\mathrm{u}$ \\
$\varnothing$ & $\mathrm{i}$ \\
\hline
\end{tabular}

\begin{tabular}{cc}
\hline Long & Symbol \\
\hline I $ى$ & $\overline{\mathrm{a}}$ \\
9 & $\overline{\mathrm{u}}$ \\
$\mathrm{g}$ & $\overline{\mathrm{1}}$ \\
\hline
\end{tabular}

\begin{tabular}{cc}
\hline Diphthong & Symbol \\
\hline$\dot{s}$ & au/aw \\
g & ai/ay \\
\hline
\end{tabular}

\section{Copyrights}

Copyright for this article is retained by the author(s), with first publication rights granted to the journal.

This is an open-access article distributed under the terms and conditions of the Creative Commons Attribution license (http://creativecommons.org/licenses/by/4.0/). 